\title{
Estatuto do Embrião Humano: Uma Visão Humanista
}

\section{Value of the Human Embrio Status: An Humanistic View}

Sandra Paço ${ }^{1}$, Sérgio Deodato²

Autor Correspondente:

\section{RESUMO}

Na atribuição de um estatuto ao embrião surgem díspares visões, podendo levar à tomada de posições diametralmente opostas em questões como abortamento, procriação medicamente assistida, diagnóstico genético pré-natal, uso de células estaminais e clonagem. Ocorrendo o desenvolvimento do ser humano num processo gradual, estas questões colocam dilemas éticos, que na sua essência têm a mesma origem, ou seja, o estatuto que se atribui ao embrião. Abordaremos, assim, esta temática através de diversas fontes, com diferentes perspetivas (biológica, ética e legal), tendo como foco de análise o estatuto atribuído ao embrião humano. Este estudo analisa alguns autores da bioética, sobretudo os de inspiração humanística e personalista, complementando-se esta perspetiva com a análise de alguns pareceres do Conselho Nacional de Ética para as Ciências da Vida, de acordo com os valores da José de Mello Saúde. Na dimensão jurídica, analisam-se os principais normativos relacionados com a vida intrauterina, assim como alguns autores desta área. Pretendemos desta forma contribuir para o aprofundamento da reflexão ética no domínio do início da vida, nomeadamente as questões éticas e jurídicas relacionadas com o estatuto do embrião humano.

PALAVRAS-CHAVE: Início da Vida Humana; Investigação com Embriões; Obrigações Morais; Pessoalidade; Regulamentação Governamental; Valor da Vida

\section{ABSTRACT}

When we think about the status of the embryo different views arise and can lead to making diametrically opposed positions on issues such as abortion, medically assisted procreation, prenatal genetic diagnosis, use of stem cells and cloning etc. Occurring the development of the human being in a gradual process, these issues pose ethical dilemmas, which in essence, have the same origin - The status that is attributed to the embryo.

We will cover, this issue through different sources, with different perspectives, with the focus of analysis the status assigned to the human embryo. This study analyzes some authors of bioethics, especially the humanist and personalist inspiration complementing this approach with the analysis of a number of opinions of the National Ethics Council for Life, according to the values of José de Mello Saúde. 
In the legal dimension, we analyze the main normative (national and international) related to intrauterine life, using authors from this area. We intend in this way contribute to the deepening of ethical reflection in the field of early life, including ethical and legal issues related to the status of the human embryo.

KEYWORDS: Beginning of Human Life; Embryo Research; Government Regulation; Moral Obligations; Personhood; Value of Life

\section{INTRODUÇÃO}

Na atribuição de um estatuto ao embrião surgem díspares visões, podendo levar à tomada de posições diametralmente opostas, nas questões como abortamento, procriação medicamente assistida, diagnóstico genético pré-natal, uso de célula estaminais e clonagem. Ocorrendo o desenvolvimento do ser humano num processo gradual, estas questões colocam dilemas éticos, que na sua essência têm a mesma origem, ou seja, o estatuto que se atribui ao embrião. Abordaremos, assim, esta temática através de diversas fontes, com diferentes perspetivas, tendo como foco de análise o valor atribuído ao embrião humano. Este estudo analisa alguns autores da bioética, complementando-se esta perspetiva com a análise de alguns pareceres do Conselho Nacional de Ética para as Ciências da Vida. Na dimensão jurídica, analisam-se os principais normativos (nacionais e internacionais) relacionados com a vida intrauterina, assim como alguns autores desta área. Pretendemos desta forma contribuir para o aprofundamento da reflexão ética no domínio do início da vida, nomeadamente as questões éticas e jurídicas relacionadas com o estatuto do embrião humano., ${ }^{1,2}$

\section{EMBRIÃO HUMANO: UMA DEFINIÇÃO}

Encetamos esta a reflexão, abordando inicialmente o desenvolvimento biológico do embrião humano. Para Silva, o embrião é "ser humano em desenvolvimento até à $8^{a}$ semana de gravidez, e resulta da fecundação de um óvulo por um espermatozoide.1" Ocorre, até ao $5^{\circ}$ dia, a sua divisão em cerca de 150 células. Ulteriormente, advirá a sua implantação no útero, sem a qual o ovócito não sobreviverá.

Loureiro, ${ }^{2}$ sob perspetiva biológica de desenvolvimento embrionário, diferencia quatro estádios tradicionalmente apontados: "A fertilização"; "Aparecimento da linha primitiva"; "Aparecimento de atividade cerebral"; "Viabilidade". Todavia, existem autores que também consideram outras etapas como por exemplo, o início dos movimentos fetais. ${ }^{3}$ Embora Loureiro ${ }^{2}$ descarte esta visão por etapas, e considere este desenvolvimento um continuum, apropriamo-nos desta visão com intuito de abranger diferentes conceções, relativamente ao desenvolvimento biológico do embrião.
Como vimos, biologicamente, a primeira fase defendida para esse início será a fecundaçãoa, altura em que o património genético do novo ser, fica definido. Efetivamente, como afirma Móran " "cuando de dos realidades distintas -el óvulo y el espermatozoide-surge un tertium, na realidade nueva y distinta -el cigoto-com una potencialidade própria y una autonomia genética, ya que, aunque dependa de la madre para subsistir, su desarrollo se va a realizar de acuerdo com su próprio programa genético". Existe, então uma nova entidade biológica - o zigoto- a partir da fecundação e segundo Loureiro "estamos perante um novo organismo, dotado de informação genética autónoma e capaz de desenvolvimento, num processo de multiplicação e diferenciação celulares...."2

Contudo, cerca de 60\% dos ovócitos não culminará numa gravidez. Até à nidificação pode ocorrer a divisão do embrião ("gemelação") e a percentagem de aborto espontâneo é de cerca de 50\%, segundo Móran. Pode ainda advir degeneração em tumores do útero ou ocorrer uma gravidez anembrionária.

Para Loureiro, ${ }^{2}$ a vida humana inicia-se com a fecundação e ela decorre até ao nascimento sem sobressaltos, pelo que refuta a possibilidade da divisão em estádios em que se possa atribuir valor crescente ao embrião.

Esses estádios defendidos por alguns autores são a fecundação; a implantação no útero, aparecimento de atividade cerebral e a viabilidade.

A fecundação para Castro 5 significa "Ia constituición de um nuevo individuo por la union de los gametas...; individuo que en el primer estádio del desarrollo embrionário consta de una sola célula y recebe el nombre de cigoto". Dura cerca de 25 a 30 horas e é neste período que ocorre a penetração do espermatozoide no óvulo. Segue-se a Singamia "o unión de gametas por lá fusión de menbranas y penetracion del espermatozoide" que "es el momento crucial en el que podemos hablar de processo de estabelecimento de um nuevo organismo que tiene um 'telos' interno". Este é considerado o estado unicelular que advém da conjugação do gâmeta feminino e do masculino.

A "gemelação" pode ocorrer nesta fase e para Castro ${ }^{5}$ "se há recurrido a la gemelación para negar la característica

a. "por fecundación se entende la constituición de um nuevo individuo por la union de los gametas...; individuo que en el primer estádio del desarrollo embrionário consta de una sola célula y recebe el nombre de cigoto" Castro, 2008,p.55 
de individuo humano al embrión temperano". Para este autor, não existem seres humanos com o mesmo património genético, pois cada ser é único e irrepetível.

A implantação ${ }^{b}$ no útero ocorre cerca do $12^{\circ}-14^{\circ}$ dia e este é o momento em que se inicia a interação entre a mãe e o zigoto. Há uma entidade independente, mas que a partir daqui está dependente do meio ambiente para o seu desenvolvimento. Para Castro esta é uma fase crucial para a sobrevivência do zigoto, mas evidentemente "desde a fecundación se pone em marcha un programa de desarrolo epigenético en el que no hay ningún momento privilegiado, ni ningún momento de solución de continuidade". 5

Outra fase referida é o momento em que se inicia a atividade cerebral. Podem-se, no entanto, colocar novos dilemas, caso do bebé anencéfalo, que não tendo cérebro, não deixará de ser humano.

Para alguns autores, como Mclean et al, ${ }^{6}$ a perceção dos movimentos fetais provoca uma significativa mudança no estatuto do embrião. Atualmente, esta perceção dos movimentos fetais, tem pouca expressão, uma vez que só diz respeito à mãe. Este argumento é também pouco fiável, visto os movimentos se iniciarem muito antes da sua consciencialização pela grávida, sendo hoje em dia, com a tecnologia existente, passível de comprovação. Presentemente, o equivalente, será a viabilidade fetal, ou seja, a etapa em que o feto pode sobreviver fora do útero materno.

Relativamente à viabilidade, é relevante mencionar a não vinculação exclusiva ao tempo fetal, mas também ao tipo de condições em que nascerá e as facilidades médicas existentes no local. Assim, este conceito altera-se, consoante evolui a ciência médica e se desenvolve a tecnologia. Presentemente, com os inúmeros avanços atuais, é possível que um feto de 22 semanas sobreviva, pelo que emerge a proteção dos seus direitos.

\section{ESTATUTO DO EMBRIÃO: UMA VISÃO HUMANISTA}

Desta forma, tentamos expor alguma diversidade de conceitos exposta na literatura consultada e que nos permitem ter uma alusão a diferentes pontos de vista acerca do início de vida humana, e não subsiste dúvida que em termos biológicos ela se inicia no momento da fecundação. ${ }^{5}$ Constatamos que para granjear o estatuto de "pessoa", todos os seres humanos percorrem esta fase de desenvolvimento e, portanto, a vida humana inicia-se com o ovócito e desenvolve-se continuamente, até ao seu término que culminará com a morte num lento e contínuo processo. Como Serrão afirma "Uma vez constituida, esta célula desenvolve um programa próprio de crescimento contínuo, inscrito no genoma, em interacção com factores epigenómicos, e cuja expressão só termina com a morte corporal".

Há um reconhecimento geral de que o embrião humano, se não existir nenhuma intercorrência, inevitavelmente dará origem a indivíduo da espécie humana. Coloca-se, no entanto, a questão de qual o momento em que se considera pessoa.

Na legislação, o desenvolvimento contínuo do feto, confere progressivos direitos e proteção pela lei, como veremos adiante. Note-se, que a partir da $24^{a}$ semana só é permitido o aborto, caso exista necessidade de salvar a vida da mãe ou para proteção da sua saúde. ${ }^{8}$ Contudo, o feto só é pessoa legal ao momento do seu nascimento e como acrescenta a lei, "e com vida". 9 Durante o processo do parto não possui ainda este estatuto.

Relativamente ao conceito ontológico de Embrião, a questão incide principalmente sobre os atributos que serão necessários para que se atribua, ou não, requisitos para ser "pessoa" ao embrião. Não sendo este campo objetivo, como a questão biológica, partilhamos apenas alguns desses atributos e opiniões existentes, com intuito de expor essas diferenças, mas sem pretensão de as aprofundar. Assim, sob o ponto de vista filosófico, e segundo Hadley, ${ }^{10}$ alguns autores defendem que o início de vida humana biológica, não é equivalente a ser "pessoa". Os atributos significativos nesta perspetiva, para ser pessoa, são a consciência, a racionalidade, a capacidade de se relacionar e comunicar e o sentido de passado e futuro. A personalidade é, assim, considerada um estado social e não um estado biológico. ${ }^{10}$ Se esta perspetiva for a assumida, desclassificar-se-ia de "pessoa", todos aqueles que não possuem estes predicados, como embriões/ fetos, pessoas inconscientes e crianças recém-nascidas. Todavia, estas formas de vida encerram dignidade humana intrínseca e, portanto, como tal, merecem respeito. Não será também de desprezar que sendo vida humana frágil, Ihe deveriam ser atribuídas proteções especiais. Efetivamente, assiste-se hoje, a um elevado investimento no nascimento de prematuros. Assim, apesar do não reconhecimento dos direitos fetais na legislação, estes são, valores enraizados no pensamento médico, legal e moral. ${ }^{10}$

Assim, mesmo para quem defende que a existência de "pessoa" como subjacente à aquisição de determinadas características intelectuais e relacionais, subsiste, na dúvida o respeito pela forma inicial da vida. ${ }^{11}$ 
O aparecimento de novas tecnologias, obriga a legislação a uma adaptação às novas circunstâncias. Nesse sentido, procederemos à análise, do quadro legal em Portugal, para enquadramento do embrião humano.

Como declarado, anteriormente, juridicamente o feto só é pessoa legal ao momento do seu nascimento, e com vida. ${ }^{9}$ Colocam-se, desta forma, várias questões: Dentro desta perspetiva o embrião poderá ser considerado pessoa? Não merecerá algum respeito, como forma inicial de vida? Qual a proteção jurídica e moral que Ihe devemos conceder?

Para Melo, o direito à vida é o "primeiro dos direitos fundamentais constitucionalmente consagrados". ${ }^{12} \mathrm{O}$ Direito à vida, resultante da proteção da Dignidade da pessoa humana, assume consagração constitucional. $\bigcirc$ artigo $24^{a}$ da Constituição atual estabelece, no seu número 1, que a "A vida Humana é inviolável", e no número 2, que "Em caso algum haverá pena de morte".

Partindo destas premissas legais, assomam incertezas, relativamente aos direitos a atribuir a embriões e fetos.

As situações de exclusão de ilicitude relativamente ao aborto, indicam a existência de situações em que se considera a existência de valores, que se sobrepõem à vida de embriões/fetos, quando em confronto com outros direitos. Segundo parecer do Conselho Nacional de Ética para as Ciências da Vida (CNEVC) ${ }^{13}$ seria importante perceber-se o alcance (ou limites) do número 1 deste artigo, uma vez que não define onde se inicia a vida humana, correndo-se o risco de "coisificação do embrião ou feto".

Efetivamente, as várias interpretações da lei vigente, suscitam divergências. Para Patto, ${ }^{14}$ não existe distinção entre a vida intra e a extrauterina, no artigo $24^{\circ} \mathrm{da}$ CRP. Apesar de todos os argumentos a favor do aborto, este autor considera que a dignidade da pessoa humana não cessa na ausência das características que a definem como tal (caso da pessoa em coma, que não deixa de ter dignidade devido à sua condição), pois "É o ser pessoa, e não actuar como pessoa, que funda a dignidade que Ihe é inerente".14 Este autor, apela para o princípio da precaução já defendido pelo CNECV, ou seja, em caso de dúvida sobre se o feto e o embrião devam ser considerados como pessoas humanas, devem ser tratados como tal. Também Lobo Xavier, afirma a não existência de distinção, quanto ao estádio de desenvolvimento do ser humano. Desta forma, referindo-se à Constituição "será legítimo afirmar, que perante o artigo 24, n' 1, toda a vida humana tem igual valor e, por isso, merecerá idêntica tutela ${ }^{15}$

Existem acórdãos do Tribunal Constitucional ${ }^{16}$ que consideraram que a norma do número 1 do Artigo $24^{\circ}$ da
Constituição Portuguesa, quando se refere à vida, inclui a vida intra e a extrauterina, inferindo-se que o Tribunal Constitucional considera a vida intrauterina um bem jurídico, constitucionalmente relevante e, portanto, digno de proteção pela ordem jurídica nacional.

Surge, todavia, um problema jurídico, quando remetemos ao artigo $66^{\circ}$ do Código Civil, uma vez que este afirma (como já vimos) que "a personalidade jurídica só se adquire com o nascimento completo e com vida. ${ }^{17 "}$ Portanto, juridicamente, não é possível considerar que o feto seja titular do direito à vida.

De facto, apesar do embrião/feto encontrar no número 1 do artigo $24^{\circ}$ da CRP alguma proteção, o artigo $66^{\circ}$ do Código Civil não parece permitir que o embrião goze do direito à vida, uma vez que apenas após o nascimento se é titular de direitos.

O Código Penal, no capítulo "Dos crimes contra a vida uterina" ${ }^{18}$ reafirma o aborto como um crime, punindo-o com pena de prisão de dois a oito anos, quem fizer abortar a mulher sem o seu consentimento. É também penalizada, com pena de prisão até três anos, a mulher que aborta e quem pratica o ato no caso do aborto consentido, fora dos termos da lei. Pode assim concluir-se que apesar da Lei da IVG, o aborto continua a constituir um crime, sempre que realizado fora das situações de exclusão da ilicitude aí mencionadas. Apesar de a lei permitir o aborto em determinadas circunstâncias, não tem implícito que essa seja a atitude correta e eticamente considerada "boa". A lei tem como pretensão, a proteção do direito à autodeterminação da mulher, no que diz respeito às escolhas reprodutivas, mas não afirma a sua defesa e total liberalização.

Na Convenção Europeia dos Direitos do Homem e da Biomedicina, de 1997, há, também, referência à vida intrauterina, atribuindo alguns direitos ao embrião/feto. ${ }^{19}$

Assim, perante possibilidade de agressão e tanta vulnerabilidade, será necessária a existência de uma tutela jurídica mais consistente de forma a proteger-se esta forma inicial de vida. Será também necessário que a legislação seja clara, não permitindo dúbias interpretações.

Retomando a perspetiva ética, importa analisar com maior detalhe os pareceres do Conselho Nacional de Ética para as Ciências da Vida. $\bigcirc$ primeiro parecer do CNECV acerca desta questão data de 1993, em que se conclui que "enquanto esta controvérsia não for resolvida e subsistir a dúvida, tem aplicação, entretanto e sempre, o princípio ético que estabelece ser gravemente ilícito atentar contra uma entidade que se duvida se, sim ou não, constitui um sujeito investido de plena dignidade humana. ${ }^{20 "}$ 
Mais tarde, no Parecer 15/ CNECV/95 conclui-se que o embrião humano é um estado inicial de vida humana, uma vez que "garantidas as necessárias condições, e se vencidos os escolhos que se opõem à sua implantação e crescimento intra-uterino, o embrião não pode deixar de dar origem a um representante da espécie humana, e nunca desembocará num indivíduo de qualquer outra espécie. ${ }^{21 "}$ Relativamente ao Princípio da Gradualidade (crescente grau de respeito pelo embrião) acrescenta que "(...) a vida humana merece respeito qualquer que seja o seu estádio ou fase, devido à sua dignidade essencial. O embrião é em qualquer fase e desde o seu início os suportes físicos e biológicos indispensáveis ao desenvolvimento da pessoa humana e nele antecipamos aquilo que há-de vir a ser: não há, pois, razões que nos levem a estabelecer uma escala de respeito.21"

No Parecer 19/CNECV/97, são reforçadas as apreciações anteriores e mantém-se o mesmo juízo, declarando "que o embrião e o feto são sede de vida humana, evoluindo inexoravelmente para a plenitude de pessoa, caso sobrevivam aos muitos obstáculos que no seu percurso vital se Ihes podem deparar. Por isso mesmo, a vida intra-uterina constitui um bem jurídico criminal, sendo penalizada a intervenção que Ihe ponha fim, a não ser que certas causas, inequivocamente graves, excluam a ilicitude de tal acção. ${ }^{22 " ~ R e l a t i v a-~}$ mente ao aborto, acrescenta este parecer que "A vida humana, mesmo incipiente, é um bem e a grávida não pode dispor livremente desse bem, que não é seu, já que o novo ser vivo necessita de protecção e sustento para continuar a sua evolução de ser irrepetível, portador da dignidade própria de membro da família humana. ${ }^{22 " ~ A s s i m, ~ " o ~ s e r ~ u ́ n i c o ~ q u e ~}$ surge após a concepção fará o seu desenvolvimento de uma forma contínua até ao término da gravidez, sendo por isso difícil a atribuição de uma linha para que passe a ser humano. ${ }^{22 " ~ A s s u m e-s e ~ c o m o ~ e v i d e ̂ n c i a ~ c i e n t i ́ f i c a, ~ a ~ e x i s t e ̂ n c i a ~}$ de vida desde a conceção e sustenta-se a obrigação da aceitação deste facto, por qualquer sociedade laica, não podendo ser considerado um dogma religioso. Afirma-se que "o embrião não pode deixar de dar origem a um representante da espécie humana, e nunca desembocará num indivíduo de qualquer outra espécie. ${ }^{22 "}$

Este Conselho teve oportunidade de se pronunciar posteriormente, relativamente à investigação em células estaminais, ${ }^{23}$ e apesar de reconhecer as expetativas criadas pelas suas possibilidades terapêuticas, considera eticamente inaceitável a criação de embriões para investigação, assim como a destruição de embriões criopreservados. No Parecer 48/CNECV/06 (Parecer sobre clonagem humana, abril de 2006) considera, relativamente à clonagem, que "independentemente da viabilidade da clonagem com finalidade reprodutiva, esta deve ser proibida porque viola a dignidade humana" 24 e não aceita esta possibilidade com embriões humanos. Eticamente, e considerando a opinião emitida por este Conselho pode afirmar-se, que independentemente da fase em que se encontre o embrião humano, o mesmo granjeia o respeito equivalente à vida humana, considerando a sua dignidade essencial. Declina-se, desta forma, a existência de uma escala gradual de respeito consoante o desenvolvimento do mesmo.

A Convenção dos Direitos do Homem e da Biomedicina, assumiu também a sua posição perante esta questão, afirmando no seu artigo $18^{\circ}, n^{\circ} 1$ "a lei deve proteger adequadamente o embrião sempre que seja autorizado a usá-lo em investigações". Proíbe depois no número 2 do mesmo artigo a constituição de embriões, apenas para uso em investigação.

\section{CONCLUSÃO}

A reflexão acerca do estatuto a atribuir ao embrião humano, não pretende esgotar-se neste artigo. Fica, no entanto, claro que será sobre a análise de várias perspetivas que a atribuição de um estatuto ao embrião será realizada. No nosso ponto de vista devemos sobretudo ter em conta a dignidade da vida na sua plenitude, o que nos obriga a considerar a vida humana inviolável, em qualquer das fases em que esta se encontre. Ao embrião deve ser reconhecido o valor jurídico de vida humana, pelo que a lei deve ser clara quanto à sua proteção.

Se o profissional de saúde defende o início de vida humana, com a conceção de todas as ações que ocorram depois deste momento, e que ponham essa vida em risco, constituirão um atentado aos princípios e valores desse profissional. Assim, a legislação confere o direito à objeção de consciência, permitindo sob escusa legal, a não participação em atos como aborto ou algumas técnicas de procriação medicamente assistidas que violam a vida do embrião.

Fica, também, claro que a atribuição de um estatuto para o embrião será uma tarefa complexa, que origina posições divergentes, pelo que o direito à objeção configura a proteção do direito à opinião e respeita a multiculturalidade das sociedades atuais.

É certo, que neste mundo de indefinições, será sempre de proteger a vulnerabilidade daqueles, que não o sendo ainda, possuem o potencial para vir a ser "pessoa".

CONFLITOS DE INTERESSE: Os autores declaram não ter qualquer conflito de interesse na realização do presente trabalho.

FONTES DE FINANCIAMENTO: Não houve qualquer fonte de financiamento na realização do presente trabalho. 


\section{REFERÊNCIAS}

1. Silva MO. Ciência, Religião e Bioética no início da vida. Alfragide: Caminho; 2006.

2. Loureiro JC. Estatuto do Embrião In: Archer L, Biscaia J, Osswald W, Renaud M, editores. Novos Desafios à Bioética. Porto: Porto Editora; 2001.

3. Mason JK, Laurie GT. Law and Medical Ethics. $7^{\circ}$ ed. Oxford: Oxford Press; 2006.

4. Móran LG. Aborto. Un reto social moral. Madrid: Comillas; 2009.

5. Castro I N. La dignidadd del embrión. Reflexiones en torno a la vida humana naciente. Madrid: Comillas; 2008.

6. Mclean S, Mason JK. Legal and Ethical Aspects of Healthcare. London: GMM; 2003.

7. Serrão D. Livro Branco. Uso de embriões humanos em investigação científica. [consultado 20 set 2016] Disponível em: http://danielserrão.com/fotos/GCA/livrobranco.pdf.

8. Decreto-Lei 16/2007, Diário da República. $1^{a}$ série. N. 75, 7 de março de 2007.

9. Decreto-Lei 47344/2007, Diário da República. $1^{\text {a }}$ série. N. 44, 25 de novembro de 1966, atualizado até à Lei 103/2009, artigo $66^{\circ}$.

10. Hadley J. Between Freedom and Necessity. In: Peterson K. editor. Medical law international. Georgetown: Georgetown University; 1996.

11. Singer P. Practical Ethics. $2^{\mathrm{a}}$ ed. New York: Cambridge University Press; 2007.

12. Melo H, Nunes R. A Ética e o Direito no Início da vida Humana. Coimbra: Gráfica de Coimbra; 2001

13. Conselho Nacional de Ética para as Ciências da Vida. Relatório-Parece sobre os Projectos de Lei Relativos à Interrupção Voluntária da Gravidez. Lisboa: CNECV; 1997.
14. Patto PV. No cruzamento do direito e da ética. Coimbra: Edições Almedina; 2008

15. Lobo Xavier R. O respeito pela vida humana não nascida e respectiva tradução no ordenamento jurídico português. Actas Colóquio de Bioética. Braga: Universidade Católica Portuguesa; 2005.

16. Acórdão 25/84, de 19 de março; Acórdão 85/85, de 29 de maio; Acórdão 288/98, de 18 de Abril.

17. Código Civil. Artigo 66을 alínea 1.a. Coimbra: Coimbra Editora; 1980.

18. Código Penal. Livro II- Parte Especial/ Título I - Dos crimes contra as pessoas / Capítulo II- Dos Crimes contra a vida intrauterina. Coimbra: Livraria Almedina; 2008.

19. Conselho da Europa. Convenção para a Protecção dos Direitos do Homem e da Dignidade do Ser Humano face às Aplicações da Biologia e da Medicina. Artigo 13; Artigo 14ª Artigo 18. 1997.

20. Conselho Nacional de Ética para as Ciências da Vida. Relatório-Parecer sobre Reprodução Assistida. Lisboa: CNECV; 1993.

21. Conselho Nacional de Ética para as Ciências da Vida Relatório-Parecer sobre a Experimentação do Embrião. Lisboa: CNECV; 1995.

22. Conselho Nacional de Ética para as Ciências da Vida. Relatório-Parece sobre os Projetos de Lei Relativos à Interrupção Voluntária da Gravidez. Lisboa: CNECV; 1997.

23. Conselho Nacional de Ética para as Ciências da Vida. Parecer sobre uso de células estaminais. Lisboa: CNECV; 2005.

24. Conselho Nacional de Ética para as Ciências da Vida. Parecer sobre clonagem humana. Lisboa: CNECV; 2006. 